\title{
Light-Trap Catch of the Harmful Moths Depending of Moonlight in North Carolina and Nebraska States of USA
}

\author{
László Nowinszky and János Puskás \\ University of West-Hungary, Savaria University Centre, Károlyi G. Square 4., Szombathely 9701, Hungary \\ Correspondence should be addressed to László Nowinszky, lnowinszky@gmail.com \\ Received 27 September 2012; Accepted 15 October 2012 \\ Academic Editors: T. Monnin and A. Robins
}

Copyright () 2012 L. Nowinszky and J. Puskás. This is an open access article distributed under the Creative Commons Attribution License, which permits unrestricted use, distribution, and reproduction in any medium, provided the original work is properly cited.

The present study discusses the light trapping of harmful insects depending on the moonlight, its polarized percentage, and the moon phases. The trapping data were taken from light traps of North Carolina and Nebraska States of USA. We examined five species. The maximum individual number of species was collected at new moon or near the first quarter and last quarter. The farmers can use our results to forecast their plant protecting works.

\section{Introduction}

The light trap is the most commonly used sampling device to study the daily activity of nocturnal insects. However, the effectiveness of light trapping as an insect sampling method was influenced by many environmental factors. Great many studies in professional literature are devoted to the role of the moon in modifying light-trapping catch. The conclusions are contradictory and up to this day good many questions have remained unqualified.

Some authors report an inability to detect a clear decrease in the efficiency of the light trap as a consequence of the effect of moonlight.

Williams [1] recognized that at the time of a full moon far fewer insects caught the light traps than at the time of a new moon. According to Williams [1], Williams et al. [2], and ElZiady [3], the reasons for a smaller catch at a full moon might be as follows.

(a) Moonlight reduces the activity of insects and so the active population accessible for the light trap is smaller.

(b) The light of the lamp collects moths from a smaller area in a moonlit environment.

In recent decades no scientist could give a provable answer to this question; in fact, most have not even tried.
Based on latter concept, several researchers calculated collection distances for different light-trap types under the variation of lunar cycle (Dufay [4], Bowden [5], and Nowinszky [6]). Bowden and Morris [7] made some corrections for daily catches by an index calculated from the changes of collecting distance during lunation.

The following authors explain the lower catches recorded when there is a full moon in terms of a shorter collecting distance: Vaishampayan and Shrivastava [8], Vaishampayan and Verma [9], Nag and Nath [10] also suggest that the lower catches of light traps when there is a Full Moon may be due to the stronger and brighter light of the Moon and a smaller collecting area, which are clearly physical phenomena.

Győrfi [11] attributes the much smaller numbers of insects caught by light traps at full moon to decreased activity. Nemec [12] is of the view that moths are inactive at full moon. Based on the results of their studies, Baker and Sadovy [13], Baker [14], and Sotthibandhu and Baker [15] believe that moonlight cannot influence the collecting distance. Thus, in their view, light intensity moderates flight activity.

The highest proportion of polarized moonlight is the highest at first and last quarter. The moonlight is not polarized at the time of full moon, directly before and after the full moon the moonlight polarized ratio is very low. Horváth and Varjú [16] and Warrant et al. [17] documented in detail that many insects are able to use the polarization pattern of 
the sky in daytime and at dusk formed by the setting sun and moon for spatial orientation. Nowinszky et al. [18] and Danthanarayana and Dashper [19] recorded maximal lighttrap catches of some moth species in the first and last quarter of moon, when the polarization proportion of moonlight is the highest. Based on this catch pattern Nowinszky et al. [18] suggested that the increasing rate of moonlight polarization is used as an orientation cue by night-flying insects, consequently, in the first and last quarter more individuals will be active elevating the catching probability.

Important experiments by Dacke et al. [20] proved that the African scarabaeid beetle (Scarabaeus zambesicus Péringuey) is able to navigate with the use of polarization sky pattern of moonlight. They later concluded that night-active insects may be extremely sensitive to detect the sky polarization pattern of moonlight, since they navigated with the same precision under the pale moonlight intensity (Dacke et al. [21], Warrant and Dacke [22]).

All in all, not to this day have researchers arrived at a common platform regarding the influence of the moon on the flight activity of insects and on the light-trap catch. Therefore, we examined this question in light-trap catch data of North Carolina and Nebraska (USA).

We always examined the possible influence of the collection distance of collection effectiveness in our previous works (Nowinszky [23], Nowinszky et al. [24-27], and Nowinszky and Puskás [28-30]). However, we could not carry out this investigation in our current study, because the available data collection originated from Black Light (BL) traps. The emitted light cannot be seen by the human eye, because of this fact the manufacturers do not give the luminous intensity (candelas) of the BL lamps. Because insects' eyes are sensitive to short-wave (the maximum is around $360 \mathrm{~nm}$ ) light sources, they surely have the collection distance, but we cannot calculate it.

\section{Material and Methods}

The light traps of North Carolina and Nebraska supplied a huge scientific material over the past two decades for entomological basic research, and plant protection prognostics work for the farmers. We could investigate only the data of six species, because enough catch data were found (Table 1).

In this investigation the BL traps data of USA States of North Carolina and Nebraska were used. These were downloaded from North Carolina Pest News on the Internet (http://ipm.ncsu.edu/current_ipm/pest_news.html) and the North Carolina Cooperative Extension Service (http://www.ces.ncsu.edu/) websites. The light-trap collecting data of Nebraska State were from the years 2000 and 2005 and the North Carolina State traps' material was found in years between 1994 and 2010. In these states $15 \mathrm{~W} \mathrm{BL}$ traps were in operation. The data collection was published several times each year. The data can be used by farmers in the development of pest control.

To create lunar phase divisions, we downloaded temporal data on full moons from the website of the Astronomical Applications Department of the US Naval Observatory (http://aa.usno.navy.mil/data/docs/MoonPhase.php).
We arranged data on the relative polarization of moonlight into phase angle divisions based on the study by Pellicori [31].

Data on the illumination of the environment were calculated using our own software. This software for TI 59 computers was developed by the late astronomer György Tóth specifically for our joint work at that time (Nowinszky and Tóth [32]). The software was transcribed for modern computers by assistant professor Miklós Kiss. The software calculates the illumination in terms of lux of the Sun at dusk, the light of the Moon, and the illumination of a starry sky for any given geographical location, day and time, separately or summarized. It also considers cloudiness. In this investigation we need a constant cloud value, because during the night we could not take into consideration the permanently change of clouds, and we had only one catch data for one night.

Most of our data collection is from Lenoir County in North Carolina State, that is why the sky light was calculated by Lenoir City geographical coordinates $\left(35^{\circ} 54^{\prime} 30^{\prime \prime} \mathrm{N}\right.$ and $81^{\circ} 31^{\prime} 48^{\prime \prime} \mathrm{W}$ ) by entering the clear sky, the time of the full moon in August 2003. Of course, the full moon lighting has changed slightly in different years, months, and gathering places. The measured illumination rate remained unchanged during the full moon lunar phase and the other ones. The clouds covered the sky in different degrees during each day and location of collection. It can be assumed that, however, these changes mostly cancelled each other out in different times and places. So these facts could not cause significant errors in our calculations.

The mean revolution time of the moon on its orbit around the earth is 29.53 days. This time period is not divisible by entire days, therefore, we rather used phase angle data. For every midnight of the flight periods (UT $=0 \mathrm{~h}$ ), we have calculated phase angle data of the moon. The $360^{\circ}$ phase angle of the complete lunation was divided into 30 phase angle groups. The phase angle group including the full moon $\left(0^{\circ}\right.$ or $\left.360^{\circ}\right)$ and $\pm 6^{\circ}$ values around it was called 0 .

Beginning from this group through the first quarter until a new moon, groups were marked as $-1,-2,-3,-4,-5,-6$, $-7,-8,-9,-10,-11,-12,-13$, and -14 (Waxing sector). The next division was \pm 15 , including the new moon. From the full moon through the last quarter to the new moon the phase angle groups were marked as 1, 2, 3, 4, 5, 6, 7, 8, 9, 10, $11,12,13$, and 14 (Waning sector). Each phase group consists of $12^{\circ}$ (Pellicori [31]). These phase angle groups are related to the four quarters of lunar cycle as it follows: full moon $(-2$ to +2 ), last quarter (3 to 9 ), new moon (10 to -10$)$, and first quarter $(-9$ to -3$)$.

Based on the number of specimens trapped, we calculated relative catch values by species and by broods. Relative catch (RC) is the ratio of the number of specimens caught in a given sample unit of time (1 hour or 1 night) and the average number of specimens caught in the same time unit calculated for the whole brood. If the number of specimens trapped equals the average, the value of relative catch is one. Only those nights were taken into consideration when trapping was successful. When trapping wasn't successful, there were extreme circumstances (e.g., hurricanes, heavy 
TABLE 1: The data of species examined from catching material of the Nebraska and North Carolina States (USA).

\begin{tabular}{|c|c|c|c|c|c|}
\hline \multicolumn{2}{|c|}{ Species } & \multirow{2}{*}{ Years } & \multicolumn{3}{|c|}{ Number of } \\
\hline Common name & Scientific name & & Individuals & Observing data & Nights \\
\hline European corn borer (ECB) & $\begin{array}{l}\text { Ostrinia nubilalis Hbn. } \\
\text { Lepidoptera: Pyralidae }\end{array}$ & 1994-2010 & 173840 & 7830 & 1449 \\
\hline Yellow woolly bear (YWB) & $\begin{array}{l}\text { Spilosoma virginica Fabr. } \\
\text { Lepidoptera: Arctiidae }\end{array}$ & $2001-2005$ & 25972 & 728 & 593 \\
\hline Corn earworm moth (CEW) & $\begin{array}{l}\text { Heliothis zea Boddie } \\
\text { Lepidoptera: Noctuidae }\end{array}$ & $1996-2010$ & 73100 & 2059 & 1596 \\
\hline Forage looper (FL) & $\begin{array}{l}\text { Caenurgina erechtea Cramer } \\
\text { Lepidoptera: Noctuidae }\end{array}$ & $2000-2005$ & 14304 & 1140 & 651 \\
\hline Western bean cutworm (WBC) & $\begin{array}{l}\text { Striacosta albicosta Smith } \\
\text { Lepidoptera: Noctuidae }\end{array}$ & $1998-2010$ & 61851 & 955 & 462 \\
\hline
\end{tabular}

precipitation and wind). These are not in connection with the moon, so they are as a distortion.

According to our former investigations the moonlight can decrease the insects' flight to light but never makes it impossible (Nowinszky [33]).

We have sorted relative catch values into the proper phase angle divisions and averaged them. Table 2 contains the results of our calculations.

Based on our results further significance calculations were performed to verify the effects, of all species on the polarized moonlight or polarized moonlight separating the waxing and waning sector of lunar month. These results are further shown in figures.

\section{Results}

According to our investigations, the light-trap catch of all five species is low at a full moon. In case of the yellow wooly bear (Spilosoma virginica Fabr.), the forage looper (Caenurgina erechtea Cramer), and the western bean cutworm (Striacosta albicosta Smith) a catch maximum is detectable in the vicinity of a new moon. In these cases, the connection is characterized by linear regression. In case of the other two species, the European corn borer (Ostrinia nubilalis Hbn.) and corn earworm moth (Heliothis zea Boddie) the catch is higher in the first and last quarter. However, correlation is stronger when we tested separately in two moon sections. At this last species the curves are different in waxing and waning phase, so we show results in two figures (Figures 3 and 4).

Results are shown in Figures 1, 2, 3, 4, 5, and 6.

Result of the European Corn Borer's collection is high when the proportion of polarized moonlight is highest both waxing and waning sector of the lunar month. The relationship is characterized by logarithmic functions.

The light-trap catch of the Western Bean Cutworm is also effective when the polarized moonlight is the highest. The connection is both in waxing and waning phase, and it can be described by the exponential function.

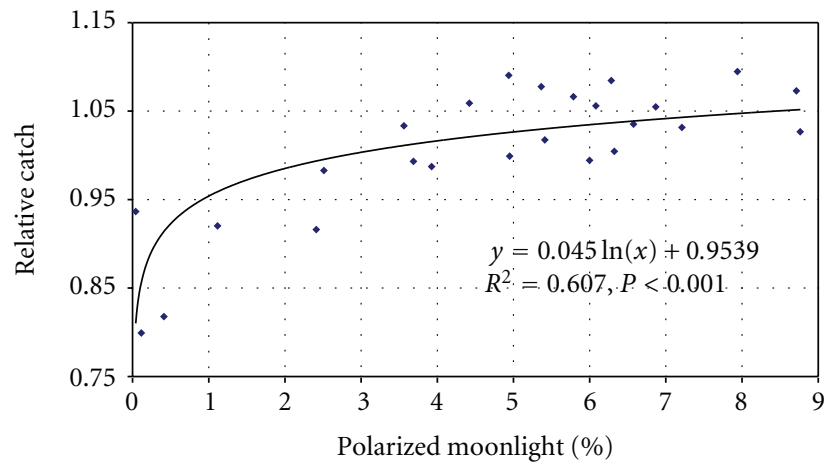

FiguRE 1: Light-trap catch of the European corn borer (Ostrinia nubilalis Hbn.) depending on polarized moonlight (North Carolina and Nebraska, 1994-2010).

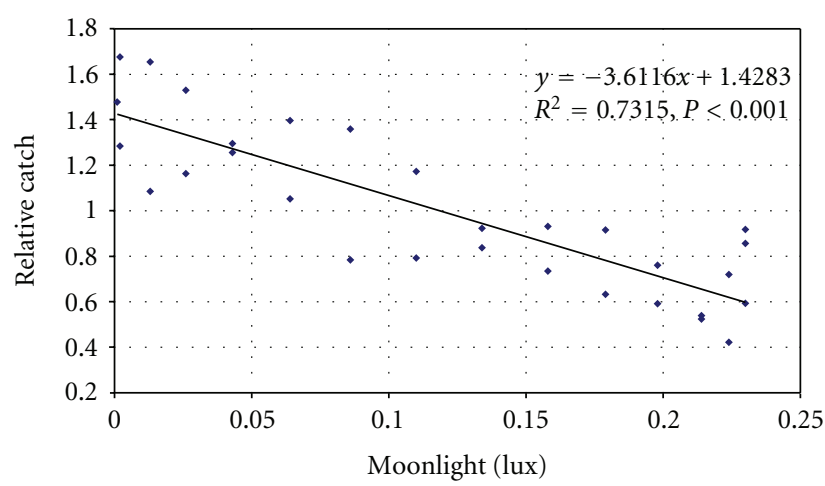

FIGURE 2: Light-trap catch of yellow woolly bear (Spilosoma virginica Fabricius) depending on the moonlight (lux) (North Carolina and Nebraska, 2001-2005).

\section{Discussion}

The degree of illumination varied periodically between the new and full moon phase during the synodic month $(29.53 \mathrm{~d})$. The illumination (Table 2 ) had a maximal value at full moon ( 0 phase division: $0.23 \mathrm{~lx})$ and a minimal value at new moon ( 15 phase division: $0.001 \mathrm{~lx}$ ). 
TABle 2: The moonlight parameters depending on the phase angle divisions (Lenoir County, for lunar month of 2003 August) and the relative catches of examined species.

\begin{tabular}{|c|c|c|c|c|c|c|c|}
\hline \multirow{2}{*}{ Phase angle divisions } & \multirow{2}{*}{ Moonlight (lux) } & \multirow{2}{*}{ Polarized moonlight (\%) } & \multicolumn{5}{|c|}{ Relative catch of } \\
\hline & & & ECB & YWB & CEW & $\mathrm{FL}$ & WBC \\
\hline 15 & 0.001 & & 1.004 & 1.478 & 1.122 & 1.427 & 1.453 \\
\hline-14 & 0.002 & & 1.047 & 1.676 & 1.146 & 1.494 & 1.442 \\
\hline-13 & 0.013 & 3.563 & 1.033 & 1.654 & 1.204 & 1.331 & 1.278 \\
\hline-12 & 0.026 & 4.422 & 1.059 & 1.530 & 1.180 & 1.194 & 1.218 \\
\hline-11 & 0.043 & 5.365 & 1.077 & 1.296 & 1.284 & 1.161 & 1.291 \\
\hline-10 & 0.064 & 6.000 & 0.994 & 1.052 & 1.262 & 1.091 & 1.399 \\
\hline-9 & 0.086 & 6.324 & 1.004 & 0.784 & 1.316 & 1.032 & 1.374 \\
\hline-8 & 0.110 & 6.576 & 1.035 & 0.792 & 1.232 & 0.946 & 1.236 \\
\hline-7 & 0.134 & 6.285 & 1.084 & 0.837 & 1.219 & 0.894 & 1.130 \\
\hline-6 & 0.158 & 5.788 & 1.066 & 0.931 & 1.075 & 0.850 & 1.014 \\
\hline-5 & 0.179 & 4.950 & 0.999 & 0.916 & 0.953 & 0.824 & 0.960 \\
\hline-4 & 0.198 & 3.687 & 0.993 & 0.760 & 0.879 & 0.773 & 0.893 \\
\hline-3 & 0.214 & 2.412 & 0.916 & 0.524 & 0.799 & 0.683 & 0.813 \\
\hline-2 & 0.224 & -0.412 & 0.818 & 0.422 & 0.714 & 0.590 & 0.607 \\
\hline-1 & 0.230 & -0.115 & 0.799 & 0.593 & 0.627 & 0.497 & 0.494 \\
\hline 0 & 0.230 & 0 & 0.807 & 0.917 & 0.622 & 0.473 & 0.448 \\
\hline 1 & 0.230 & -1.115 & 0.920 & 0.856 & 0.658 & 0.507 & 0.491 \\
\hline 2 & 0.224 & -0.041 & 0.936 & 0.719 & 0.718 & 0.577 & 0.489 \\
\hline 3 & 0.214 & 2.511 & 0.983 & 0.539 & 0.852 & 0.706 & 0.554 \\
\hline 4 & 0.198 & 3.927 & 0.987 & 0.591 & 1.027 & 0.775 & 0.628 \\
\hline 5 & 0.179 & 5.412 & 1.017 & 0.632 & 1.088 & 0.845 & 0.737 \\
\hline 6 & 0.158 & 6.869 & 1.055 & 0.734 & 1.138 & 0.963 & 0.741 \\
\hline 7 & 0.134 & 7.941 & 1.095 & 0.923 & 1.035 & 1.099 & 0.734 \\
\hline 8 & 0.110 & 8.714 & 1.073 & 1.172 & 1.049 & 1.339 & 0.701 \\
\hline 9 & 0.086 & 8.765 & 1.027 & 1.359 & 1.018 & 1.350 & 0.769 \\
\hline 10 & 0.064 & 7.212 & 1.031 & 1.397 & 1.034 & 1.318 & 0.941 \\
\hline 11 & 0.043 & 6.083 & 1.056 & 1.256 & 1.043 & 1.151 & 1.261 \\
\hline 12 & 0.026 & 4.939 & 1.090 & 1.163 & 1.027 & 1.203 & 1.484 \\
\hline 13 & 0.013 & & 1.014 & 1.085 & 1.035 & 1.145 & 1.524 \\
\hline 14 & 0.002 & & 1.022 & 1.284 & 1.039 & 1.385 & 1.502 \\
\hline
\end{tabular}

As the insects see the light of BL traps, assume that at new moon, when only the night sky light is present a larger collection distance causes the more effective catching.

The reason for the catch minimum observed during full moon may not be a relatively strong illumination caused by the moon. Most insects take wing at dusk, and the illumination values recorded during different twilights are higher than those due to moonlight. Generally, illumination by the moon does not hamper the flight activity of insects.

It is a justified fact that certain insects use polarized moonlight for their orientation. It is unthinkable that the activity of these insects would decrease when polarized moonlight is present in a high ratio.

Based on the works of Dacke et al. [20], we can presume that a high ratio of polarized moonlight presents more information for the orientation of insects than a smaller proportion of either positively or negatively polarized moonlight around the time of full moon. This may be the reason for the high catches in the first and last quarters and low ones during a full moon. The illumination due to moonlight at a full moon does not generally decrease the flight activity of insects, as proposed by Williams [1]. The point is rather that at a full moon flight activity truly decreases, as compared to that during the first and the last quarters. This might be caused by the difference in the volume of polarized moonlight, the highest during the first and the last quarters and the lowest at a full moon.

Our new results indicate that catches are high when the proportion of polarized moonlight is high (Figures 1, 3, and 4). Based on our study, we can complete and partially modify the presumption of Williams [1] that strong moonlight decreases flight activity.

There is another possibility; insects may be reluctant to fly at full moon not because light (intensity and polarization) hampers their orientation, but because light may make insects more conspicuous to predators. This is the opposite with the next study. According to Svensson and Rydell [34] bats often feed in the vicinity of street lamps. They make 


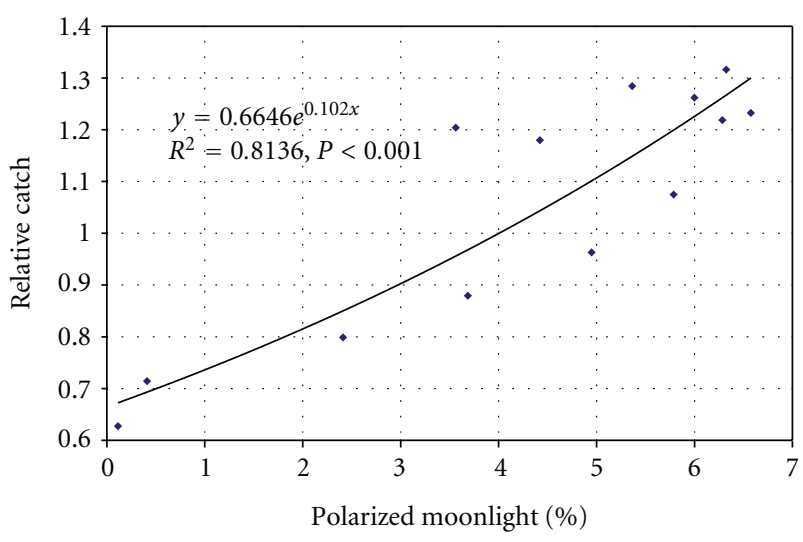

FIGURE 3: Light-trap of corn earworm math (Heliothis zea Boddie) depending on polarized moonlight in waxing section of lunar month (North Carolina and Nebraska, 1996-2010).

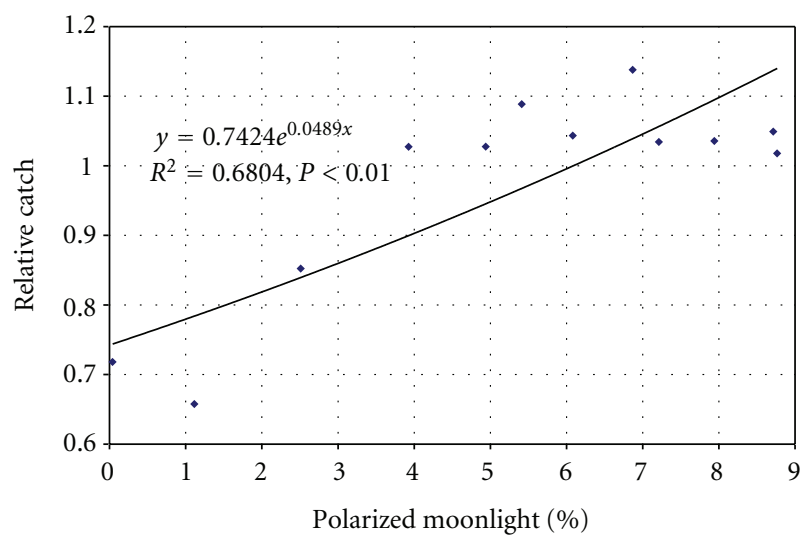

FIGURE 4: Light-trap of corn earworm moth (Heliothis zea Boddie) depending on polarized moonlight in waning section of lunar month (North Carolina and Nebraska, 1996-2010).

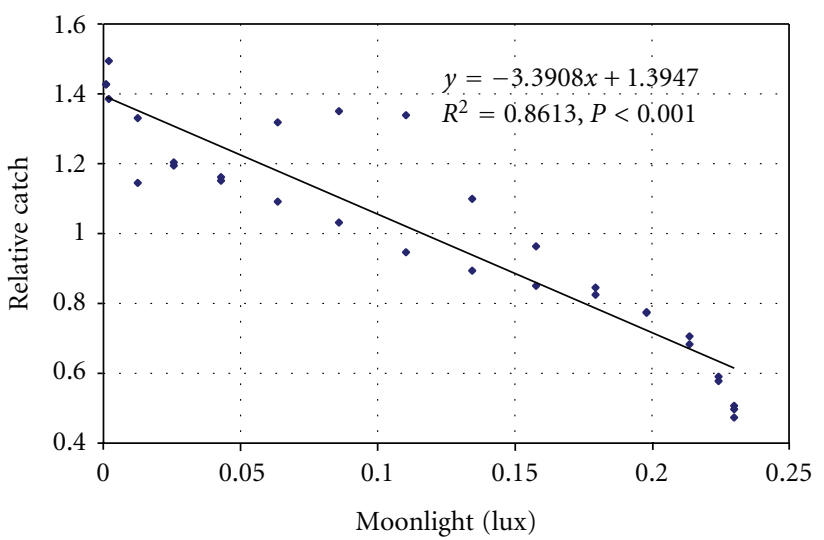

FIGURE 5: Light-trap of forage looper (Caenurgina erechtea Cramer) depending on the moonlight in waxing and waning sector of the lunar month (North Carolina and Nebraska, 2001-2005).

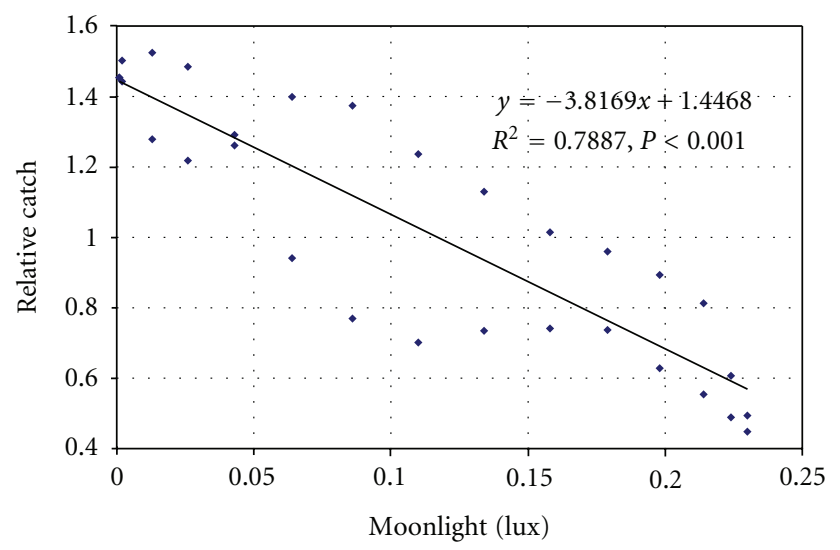

FIGURE 6: Light-trap catch of the Western bean cutworm (Striacosta albicosta Smith) depending on the moonlight in waxing and waning sector of the lunar month (North Carolina and Nebraska, 19982005).

good use of the fact that moths gather around the light. Mercury vapour street lamps confuse moths in their defence mechanism and that is why they are more endangered in the face of bats.

Our results indicate that when a high proportion of moonlight is polarized, flight activity increases but when there is a low level of polarization, as at a full moon, flight activity decreases.

The farmers can use our results to forecast their plant protecting works.

\section{Acknowledgment}

The authors thank the assistance of Professor Dr. Miklós Kiss, who transcribed our software for modern computer.

\section{References}

[1] C. B. Williams, "The influence of moonlight on the activity of certain nocturnal insects, particularly of the family of Noctuidae as indicated by light-trap," Philosophical Transactions of the Royal Society B, vol. 226, no. 537, pp. 357-389, 1936.

[2] C. B. Williams, B. P. Singh, and S. El-Ziady, "An investigation into the possible effects of moonlight on the activity of insects in the field," Philosophical Transactions of the Royal Society A, vol. 31, pp. 135-144, 1956.

[3] S. El-Ziady, "A probable effect of the moonlight on the vertical distribution of Diptera," Bulletin of the Entomological Society of Egypt, vol. 41, pp. 655-662, 1957.

[4] C. Dufay, "Contribution a l'Étude du phototropisme des Lépidopteres noctuides," Annales Des Sciences Naturelles, Zoologie, vol. 12, no. 6, pp. 281-406, 1964.

[5] J. Bowden, "An analysis of factors affecting catches of insects in light-traps," Bulletin of Entomological Research, vol. 72, no. 4, pp. 535-556, 1982.

[6] L. Nowinszky, Light Trapping and the Moon, Savaria University Press, Szombathely, Hungary, 2008.

[7] J. Bowden and G. M. Morris, "The influence of moonlight on catches of insects in light-trap in Africa. Part III. The effective 
radius of a mercury-vapour light-trap and analysis of catches using effective radius," Bulletin of Entomological Research, vol. 65, no. 2, pp. 303-348, 1975.

[8] S. M. Vaishampayan and S. K. Shrivastava, "Effect of moon phase and lunar cycle on the light trap catch of tobacco caterpillar Spodoptera litura (Fabr.) (Lepidoptera: Noctuidae)," Journal of the Bombay Natural History Society, vol. 75, pp. 8387, 1978.

[9] S. M. Vaishampayan and R. Verma, "Influence of moon light and lunar periodicity on the light trap catches of gram podborer, Heliothis armigera (Hubner) moths," Indian Journal of Entomology, vol. 44, no. 3, pp. 206-212, 1982.

[10] A. Nag and P. Nath, "Effect of moon light and lunar periodicity on the light trap catches of cutworm Agrotis ipsilon," Journal of Applied Entomology, vol. 111, no. 4, pp. 358-360, 1991.

[11] J. Győrfi, "The influence of illumination and light on insects," Erdészeti Kísérletek, vol. 48, no. 3-4, pp. 108-111, 1948 (Hungarian).

[12] S. J. Nemec, "Effects of lunar phases on light-trap collections and populations of bollworm moth," Journal of Economic Entomology, vol. 64, no. 4, pp. 860-864, 1971.

[13] R. R. Baker and Y. Sadovy, "The distance and nature of the light-trap response of moths," Nature, vol. 276, no. 5690, pp. 818-821, 1978.

[14] R. R. Baker, "Celestial and light-trap orientation of moths," Antenna, vol. 3, pp. 44-45, 1979.

[15] S. Sotthibandhu and R. R. Baker, "Celestial orientation by the large yellow underwing moth, Noctua pronuba L.," Animal Behaviour, vol. 27, no. 3, pp. 786-800, 1979.

[16] G. Horváth and D. Varjú, Polarized Light in Animal Vision. Polarization Pattern in Nature, Springer, New York, NY, USA, 2004.

[17] E. J. Warrant, A. Kelber, R. Wallén, and W. T. Wcislo, "Ocellar optics in nocturnal and diurnal bees and wasps," Arthropod Structure and Development, vol. 35, no. 4, pp. 293-305, 2006.

[18] L. Nowinszky, S. Szabó, G. Tóth, I. Ekk, and M. Kiss, "The effect of the moon phases and of the intensity of polarized moonlight on the light-trap catches," Zeitschrift für Angewandte Entomologie, vol. 88, pp. 337-353, 1979.

[19] W. Danthanarayana and S. Dashper, "Response of some nightflying insects to polarized light," in Insect Flight: Dispersal and Migration, W. Danthanarayana, Ed., pp. 120-127, Springer, Berlin, Germany, 1986.

[20] M. Dacke, D. E. Nilsson, C. H. Scholtz, M. Byrne, and E. J. Warrant, "Animal behaviour: insect orientation to polarized moonlight," Nature, vol. 424, p. 33, 2003.

[21] M. Dacke, M. J. Byrne, E. Baird, C. H. Scholtz, and E. J. Warrant, "How dim is dim? Precision of the celestial compass in moonlight and sunlight," Philosophical Transactions of the Royal Society B, vol. 366, no. 1565, pp. 697-702, 2011.

[22] E. J. Warrant and M. Dacke, "Vision and visual navigation in nocturnal insects," Annual Review of Entomology, vol. 56, pp. 239-254, 2011.

[23] L. Nowinszky, "Nocturnal illumination and night flying insects," Applied Ecology and Environmental Research, vol. 2, no. 1, pp. 17-52, 2004.

[24] L. Nowinszky, J. Puskás, and Zs. Kúti, "Light trapping as a dependent of moonlight and clouds," Applied Ecology and Environmental Research, vol. 8, no. 4, pp. 301-312, 2010.

[25] L. Nowinszky, A. Hirka, Gy. Csóka, G. Petrányi, and J. Puskás, "The influence of polarized moonlight and collecting distance on the catches of winter moth Operophthera brumata L., (Lepidoptera: Geometridae) by light-traps," European Journal of Entomology, vol. 109, no. 1, pp. 29-34, 2012.
[26] L. Nowinszky, O. Kiss, F. Szentkirályi, J. Puskás, and M. Ladányi, "Influence of illumination and polarized moonlight on light-trap catch of caddisflies (Trichoptera)," Research Journal of Biology, vol. 2, no. 3, pp. 79-90, 2012.

[27] L. Nowinszky, G. Petrányi, and J. Puskás, “The relationship between lunar phases and the emergence of the adult brood of insects," Applied Ecology and Environmental Research, vol. 8, no. 1, pp. 51-62, 2010.

[28] L. Nowinszky and J. Puskás, "Possible reasons for reduced light trap catches at a full moon: shorter collecting distance or reduced flight activity," Advances in Bioresearch, vol. 1, no. 1, pp. 205-220, 2010.

[29] L. Nowinszky and J. Puskás, "Light trapping of Helicoverpa armigera in India and Hungary in relation with the moon phases," Indian Journal of Agricultural Sciences, vol. 81, no. 2, pp. 154-157, 2011.

[30] L. Nowinszky and J. Puskás, "Light trapping of the turnip moth (Agrotis segetum Den. et Schiff.) depending on the geomagnetism and moon phases," Applied Ecology and Environmental Research, vol. 9, no. 3, pp. 303-309, 2011.

[31] S. F. Pellicori, "Polarizing properties of pulverized materials with special reference to the lunar surface," Applied Optics, vol. 10, no. 2, pp. 270-285, 1971.

[32] L. Nowinszky and Gy. Tóth, Influence of cosmic factors on the light-trap catches of harmful insects (in Hungarian) [Ph.D. thesis], Pannon University of Agricultural Sciences, Szombathely, Hungary, 1987.

[33] L. Nowinszky, Ed., The Handbook of Light Trapping, Savaria University Press, Szombathely, Hungary, 2003.

[34] A. M. Svensson and J. Rydell, "Yearly activity patterns of bats at Belair National Park in Adelaide, South Australia," Australian Mammalogy, vol. 20, pp. 369-375, 1998. 

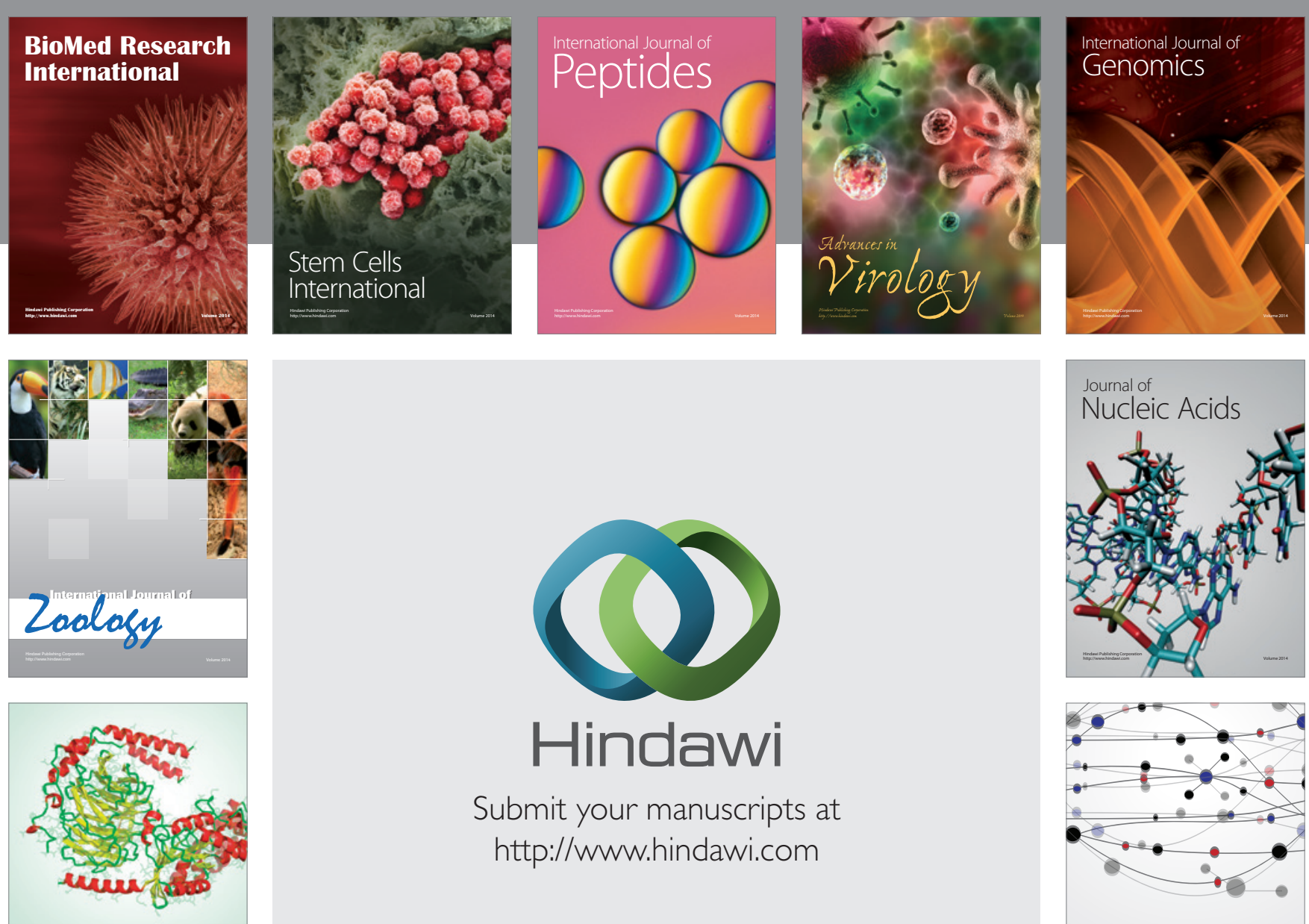

Submit your manuscripts at

http://www.hindawi.com

Signal ${ }^{\text {Jumal }}$ Transduction
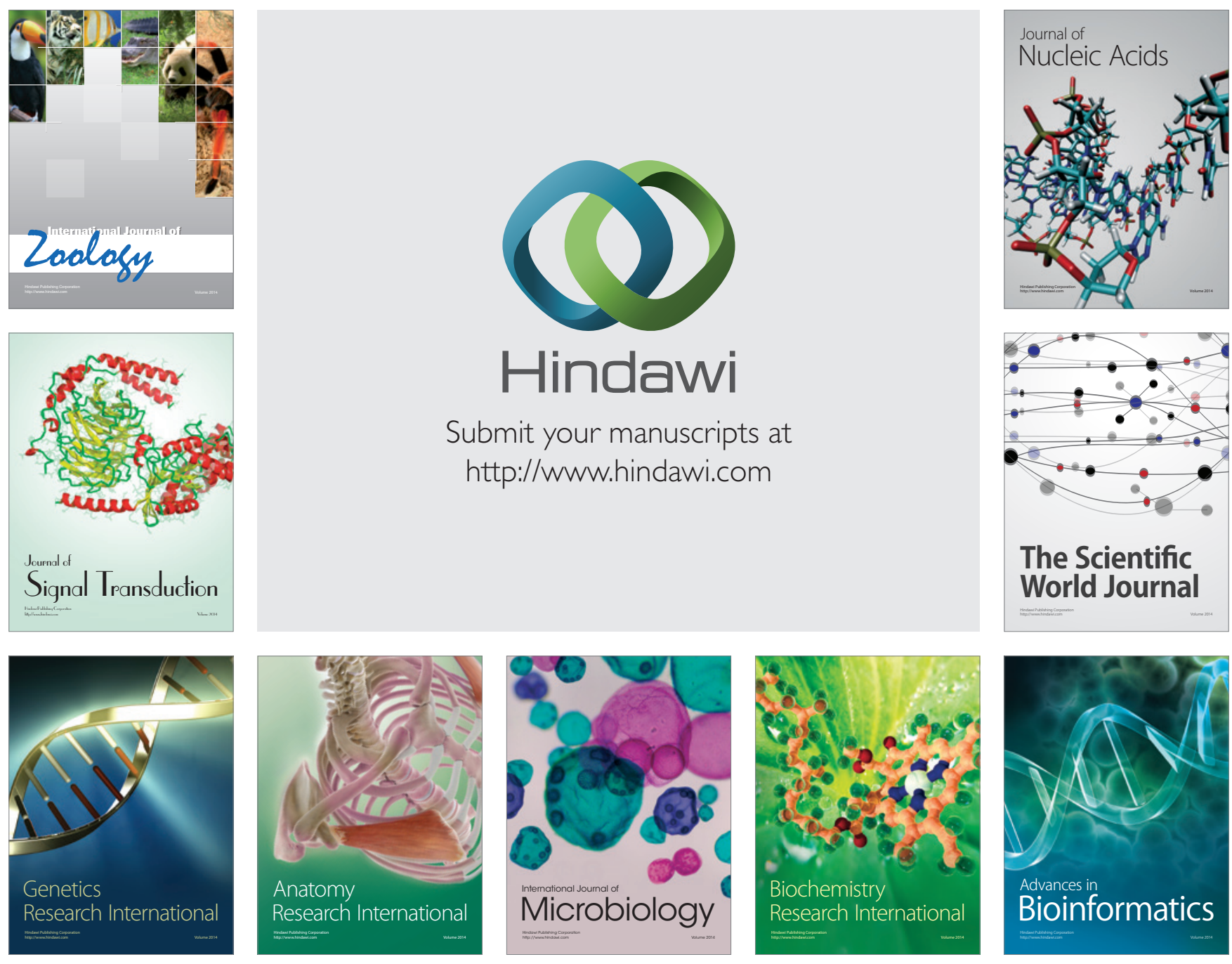

The Scientific World Journal
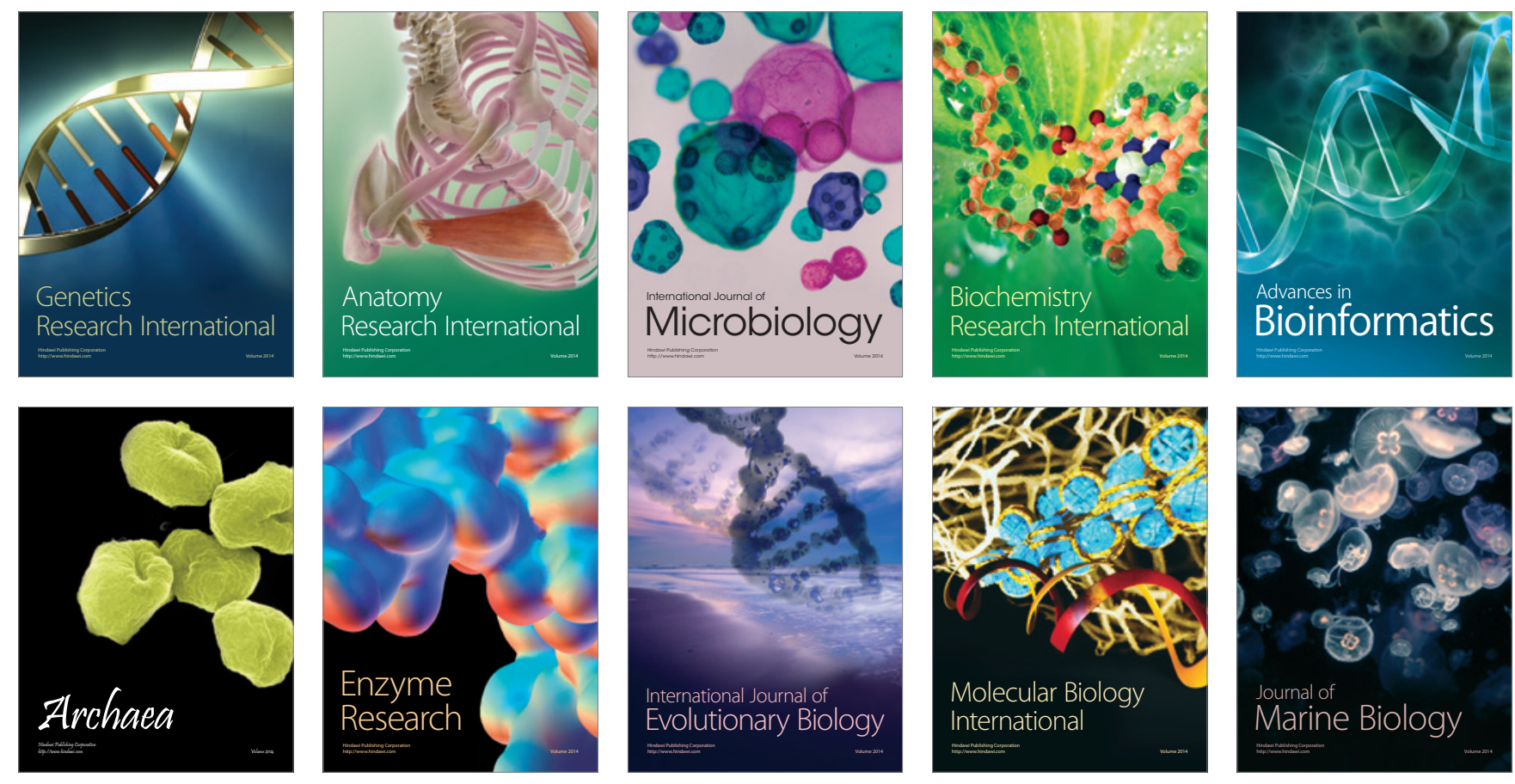